\title{
1. Host impairments in patients with neoplastic diseases
}

Ben E. De Pauw, J. Peter Donnelly, and Bart-Jan Kullberg

\section{Introduction}

In the course of evolution nature has provided the normal human individual with an impressive and effective defense system against microbial enemies that eclipses even Star Wars, arguably the most advanced and ingenious defense program ever designed by human beings. On its own, the normal defense system recognizes foreign invaders, alerts the relevant protective mechanisms, launches counterattacks, ceases hostilities as soon as the job is done, and clears up the battlefield, causing only negligible collateral damage. An intact system offers protection against most microbial aggressors through a complex interrelationship of protecting surfaces, cells, and soluble factors.

Optimal nutritional status and normal organ function form the basis of resistance to potentially dangerous microorganisms; therefore, it is somewhat artificial to further delineate the separate lines of defense [1] because all components are more or less dependent upon each other in attaining maximum efficacy. For instance, the skin and mucosal membranes are ranked amongst the first line of defense but they can only exert optimal activity in conjunction with the immunoglobulin (Ig) A and other secretory substances. Moreover, the surfaces of the human body exhibit a clear propensity to interact with colonizing microorganisms. The so-called commensal resident flora are normally avirulent, do not cause infection, and protect against more aggressive pathogens by competing for binding sites on the surfaces and for the available nutrients. Therefore, white blood cells (granulocytes, macrophages, and lymphocytes), platelets, soluble factors of the immunoglobulins, complement, lymphokines, and other cytokines, as well as the physical barriers, have to be considered as integral and virtually indispensable components of a unitary defense system (Figure 1). Given its complexity, it is not surprising that such a finely tuned system is subject to profound perturbation by therapeutic manipulation and hematologic malignancies.

Any qualitative or quantitative defect in one of the components of the human defense system may predispose to infection, which remains a major 


\section{THROMBOCYTES}

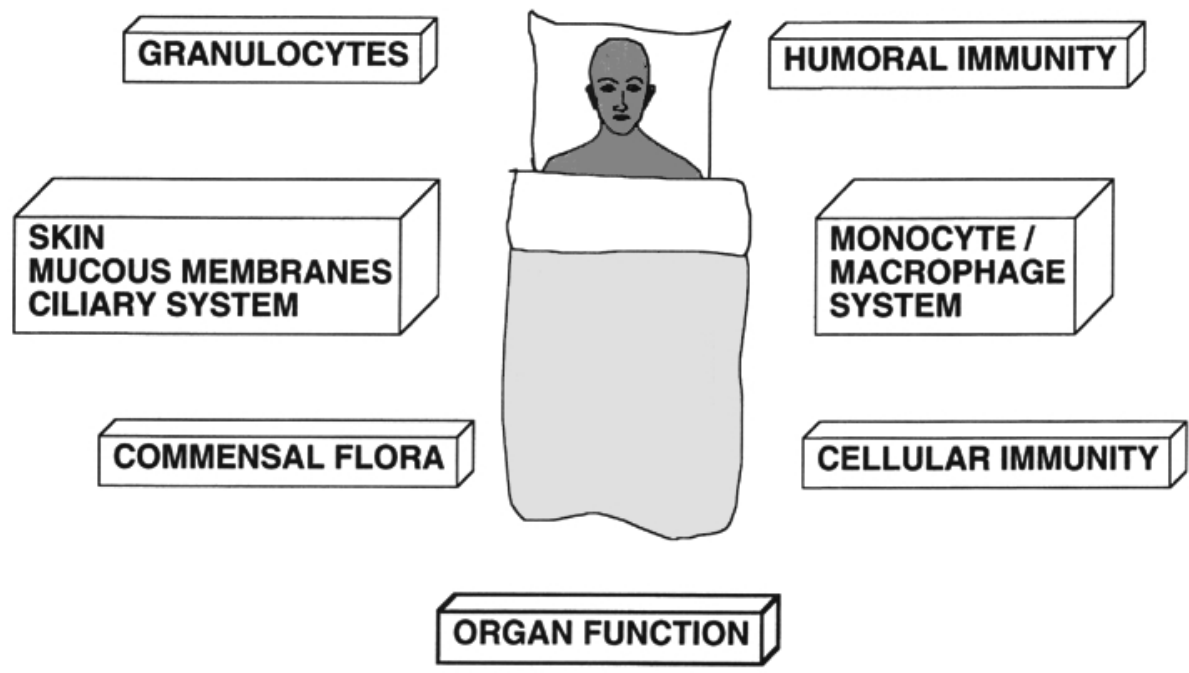

Figure 1. Normal defense systems.

cause of morbidity and mortality among patients undergoing treatment for malignancy. However, isolated deficiencies are rarely encountered because malfunction of one part of the system exerts an impact on several other parts. Moreover, therapeutic interventions and the underlying disease conspire to afflict a range of defense mechanisms. The effects of the various different noxious events that occur while treating malignancy differ in severity as well as in primary targets (Figure 2). To complicate things further, hazardous events do not remain static but rather exert their impact dynamically as the degree of disturbance varies with time during or after a course of treatment (Figure 3).

The human defense system is capable of coping with a tremendous number of insults before it finally begins to show the first signs of surrender. It should therefore be obvious to physicians that their activities put the entire defense system of patients at considerable risk. At the very least the patient should receive proper instruction on the prevention of infection and optimal hygiene should be maintained at all times. Physicians also have to select the most appropriate treatment regimen, thereby avoiding potentially dangerous medications, and to limit invasive procedures to those that are absolutely warranted. This complex interaction between host defenses and therapeutic modalities has a profound effect on patient outcome. 


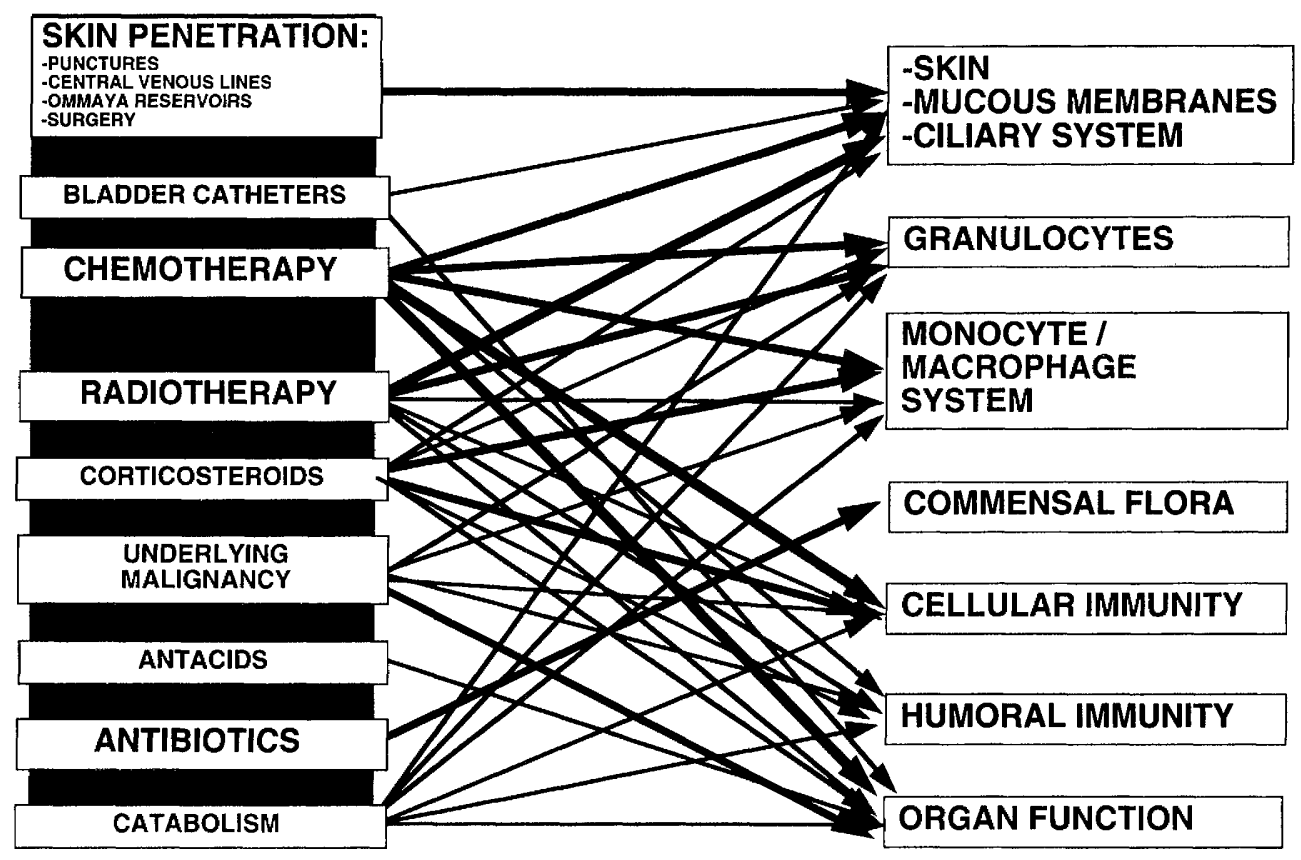

Figure 2. Factors influencing the human defense systems.

\section{Basic clinical condition and organ function}

\subsection{Nutritional status}

Weight loss correlates inversely with survival in patients with cancer. This occurs whether or not intensive treatment is given because the integrity of host defenses can be endangered by the catabolic state induced by cachexia and malnutrition, resulting in a quantitatively deficient intake of calories and protein, with insufficient vitamin levels and trace metal concentrations [2,3]. Cachexia will be exacerbated by anorexia, chemotherapy-induced nausea and vomiting, gastrointestinal obstructions, and metabolic derangements. The final extent of the damage to the defense system depends upon the degree of cachexia and malnutrition. This may result in delayed wound healing, mucosal atrophy with a decrease in the secretions of lysozyme and secretory $\operatorname{IgA}$, as well as impairment of both the classical and alternative complement pathways. A deficiency of vitamin A may also have a detrimental effect on the cellular immune system [4].

Furthermore, deficiencies of trace elements may undermine host defense in compromised patients. Zinc deficiency, as has been observed during total parenteral nutrition, generates a disturbed function of phagocytes and T cells, 


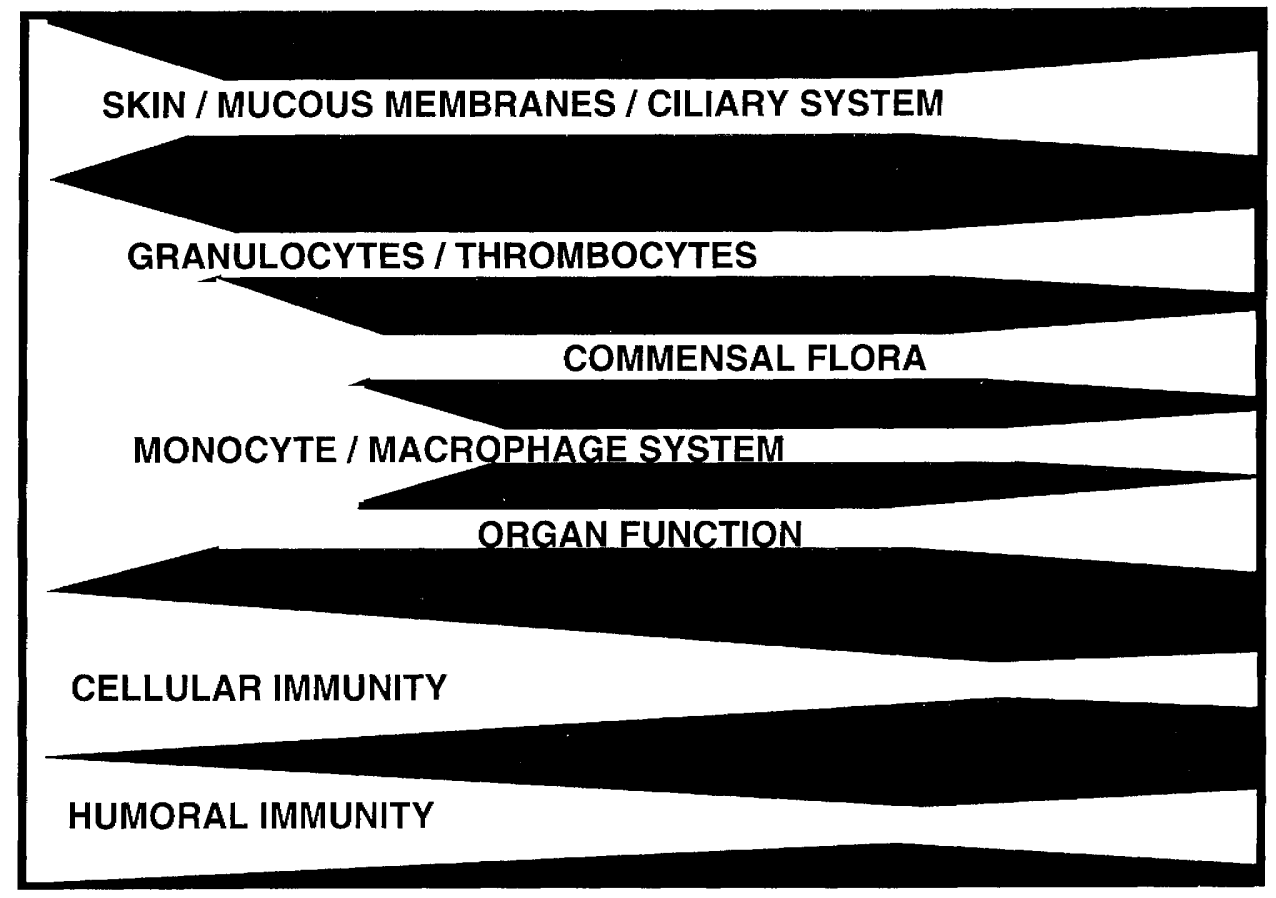

Figure 3. Evolution of impairment of defense systems after treatment for malignancy.

which can be neutralized by the addition of this mineral [5]. The in vitro microbicidal capacity of neutrophils and T-lymphocyte function are reduced in patients with iron deficiency, but it is uncertain whether this has any clinical significance. On the hand, it is well known that iron overload, a conceivable consequence of multiple blood transfusions, may lead to an increased susceptibility to infection, which is possibly related to a direct interaction between the iron available and the fungus Mucor. A phosphate deficit, which may occur during episodes of starvation and insufficient parenteral nutrition, is associated with a decrease in the chemotactic, phagocytic, and microbicidal functions of granulocytes in vitro, and clinically with bacterial and fungal infections [6].

In elderly patients, the atrophy and dryness of the skin and mucosal membranes that occurs with age may lead to an increased susceptibility to infections. In addition, the primary and secondary humoral responses, as well as the oxidative metabolism of neutrophils and T-cell functions, decline with age, but the exact role of these regularly found abnormalities with regard to susceptibility to infection is unclear [7].

Concomitant chronic illnesses enhance the risk of infection in many patients. Even mild graft-versus-host disease is deleterious to the integument [8], and patients with a pre-existing immune disturbance, such as HIV infection or 
a congenital immunodeficiency syndrome, are placed in double jeopardy. Much more common, however, is the detrimental effects of smoking, particularly in patients with primary lung tumors, due to colonization of their airways with virulent microorganisms and impaired clearance of secretions [9].

Patients with poorly controlled diabetes mellitus are more likely to develop wound infections after all kinds of skin penetrations, and they frequently suffer from concurrent vascular disease and neuropathy. High concentrations of glucose in the urine and oral secretions promotes colonization by Candida species and other pathogens [10]. Diabetes mellitus has been associated with notorious infections, such as rhinocerebral mucormycosis and malignant external otitis [11], which is not difficult to explain in view of several other aberrations that are associated with diabetes, such as impaired opsonization and decreased chemotactic activity of granulocytes and monocytes. Reduction of phagocytic adherence and defective phagocytosis, as well as bactericidal function of granulocytes, have been shown during episodes with high glucose concentrations and a low $\mathrm{pH}$, putatively due to an impaired glucose metabolism of the phagocytes. A remarkable observation in this context is the relation between myeloperoxidase deficiency and serious fungal infections in patients with diabetes [12].

\subsection{Physiological and psychological status}

Psychological stress is thought to suppress host defense mechanisms. This general assumption has been corroborated by the observations that psychological stress has a negative influence on the function of $T$ cells and NK cells. Indeed, stress appears to be connected with an increased risk of acute viral respiratory illness, a risk that is related to the amount of stress. This is most likely mediated by endogenous opioids, hormones from the hypothalamicpituitary-adrenal axis, catecholamines, and cytokines [13].

Tumors themselves may also predispose to infection by local organ dysfunction. In patients with solid tumors, obstruction of natural passages can lead to inadequate drainage of secretory or excretory fluids from nasal sinuses, bronchi, and bile ducts. Furthermore, tissue invasion may create connections between normally sterile spaces and the environment through disruption of epithelial surfaces. Examples include perforation of the esophagus by mediastinal tumors, invasive gynecological malignancies with local pelvic abscesses caused by gram-negative rods and anaerobes, skin ulcerations with cellulitis and deep soft-tissue infections, and invasion of the bowel wall by tumors of the lower gastrointestinal tract, resulting in bacteremia. Localizations in the central nervous system, spinal cord compression, and paraneoplastic neuropathy are associated with an increased risk of infection due to lethargy and, for instance, a diminished ability to cough and swallow, and incomplete emptying of the bladder [9].

Of course, hematologic malignancies are notorious for infectious com- 
plications because the neoplasm resides within the immune system itself and interferes directly and indirectly with its function. In patients undergoing splenectomy, the risk that they will develop overwhelming sepsis at some time during their life is approximately 5\%. Encapsulated bacteria such as Streptococcus pneumoniae and Haemophilus influenzae are the prevalent pathogens, but Neisseria meningitidis and staphylococci are occasionally encountered [14]. Several factors might explain this well-established increased susceptibility to microbial infection. Encapsulated bacteria are able to elude phagocytosis because specific opsonizing antibodies are necessary for efficient phagocytosis. Furthermore, a reduced level of the complement factor properdin, which may lead to suboptimal opsonization, and a decrease in functional tuftsin have both been demonstrated after splenectomy [1]. The spleen is the principal organ for eliminating particles that are not opsonized, and it is left to the macrophages that occupy strategic positions within the organ to remove them.

The primary immunoglobulin response also takes places in the spleen, and low levels of circulating IgM have been observed after splenectomy in children. Because of the risk of pneumococcal infection after splenectomy, immunization with a polyvalent pneumococcal vaccine is recommended, preferably prior to splenectomy to ensure a better immune response during later life. However, the protection from vaccination is probably limited to several years, and, although vaccination has been shown to be effective, infection still may occur [15]. Therefore, for children it is recommended that vaccination be supplemented by antibiotic prophylaxis. In splenectomized adults suffering from a hematologic malignancy, patient-initiated treatment with oral amoxicillin at the onset of fever should be considered because the response to vaccines is usually suboptimal in patients with pre-existing immune deficiencies.

\section{Integument and commensal microflora}

The integument comprises the skin, respiratory tract - including the nasal cavity, ears, and conjunctiva - the alimentary tract, and the genitourinary tract (Figure 4) and provides the first line of defense against microbial invasion. In physical terms the only difference between the skin and the other parts of the integument is that it is dry, whereas the others are bathed in mucins and therefore continually moist. Thus, while both surfaces are normally colonized with a variety of microorganisms, including many different genera of bacteria and yeasts, the range and number of species and the biomass associated with mucosal surfaces is much greater than those of the skin. However, the resident microbial flora of each surface play an integral role in helping maintain the function and integrity of these first lines of defense. Moreover, when intact and healthy, both the mucosa and skin are capable of resisting colonization with foreign or allochthonous organisms found in the immediate environment and 


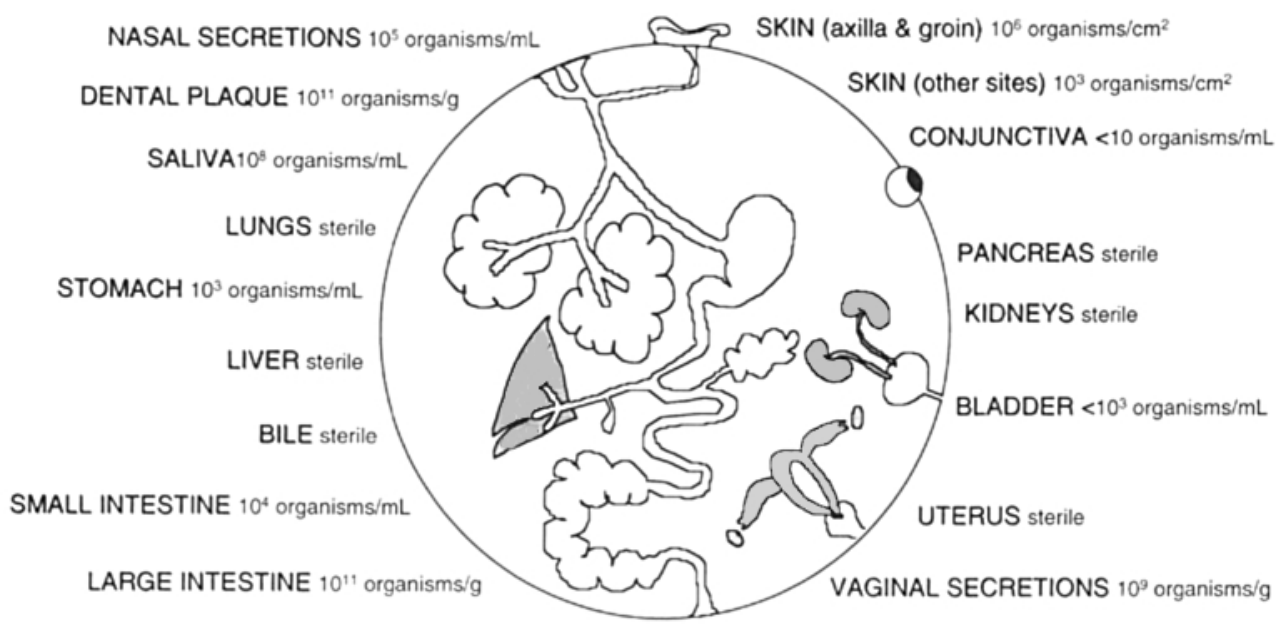

Figure 4. Body surfaces and their resident microbial flora. The integument comprises the skin, respiratory tract - including the nasal cavity, ears, and conjunctiva - the alimentary tract, and the genitourinary tract, and provides the first line of defense against microbial invasion. These body surfaces are normally colonized with a variety of microorganisms, including many different genera of bacteria and yeasts, but the range, number of species, and microbial biomass associated with the mucosal surfaces of the alimentary tract far exceed those of the skin.

maintaining an ecological balance within the indigenous microbial flora as a result of intimate host-parasite interactions.

\subsection{Skin}

The skin of an adult has an estimated surface area of $1.5-2.3 \mathrm{~m}^{2}$ and possesses features that are inimical to microbial invasion, provided it remains healthy and intact. The cells are composed of keratin and resemble loose paving stones. They are joined together by desmosomes and are continually sloughed off during desquamation so that adherent bacteria are also lost. This rapid cell turnover occurs every 2 weeks and helps to limit the opportunities for transient organisms to establish residence. Resident flora also have to continually re-establish themselves and do so because they are able to attach quickly.

In ecological terms, the skin presents an arid milieu even though its humidity exceeds $90 \%$ because there is, in biological terms, very little water available for microorganisms due to the production of sebum, which is composed of lipids including triglycerides, long chain fatty acids, wax, and cholesterol esters, squalene, and other lipophilic substances. This oily, parched environment is particularly hostile to the establishment of microbial settlements involving gram-negative bacteria, which are vulnerable to desiccation and require an aqueous environment for survival. Moreover, only those microorganisms that elaborate lipases are capable of acquiring carbon from these 
Table 1. Microbial residents of the normal skin

\begin{tabular}{lll}
\hline Major group & Genus & Opportunistic pathogens \\
\hline Gram-positive cocci & $\begin{array}{l}\text { Staphylococcus spp. } \\
\text { Micrococcus } \text { spp. }\end{array}$ & S. epidermidis \\
Gram-positive bacilli & $\begin{array}{l}\text { Corynebacterium } \text { spp. } \\
\text { Brevibacterium } \text { spp. } \\
\text { Propionibacterium } \text { spp. } \\
\text { Acinetobacter } \text { spp. } \\
\text { Pityrosporum } \text { spp. }\end{array}$ & C. jeikeium \\
Yeasts & A. baumanida spp. & C. parapsilosis \\
\hline
\end{tabular}

lipids. The skin also forms an acid mantle, having a $\mathrm{pH}$ of $5.0-6.0$, and its surface temperature is, on average, about $5^{\circ} \mathrm{C}$ lower than that of the core body temperature. Sweat and transepidermal water loss introduce water to the surface of the skin, which contains a range of potential carbon and nitrogen sources, including lactate and pyruvate, glucose, amino acids, creatinine, urea, and urocanic acid.

However, the resident flora modulate the microecology of the skin by releasing fatty acids, such as oleic, stearic, and palmitic acids, from the sebaceous secretions, as well as short-chain lactic and propionic acids, resulting in a hydrophobic, acid milieu, which counterbalances the nutrient potential of sweat. IgA is also secreted in sweat. Thus the range of organisms that are able to reside on the skin is strictly limited to a few, mainly gram-positive bacteria, such as various members of the coagulase-negative staphylococci, particularly Staphylococcus epidermidis, Corynebacterium jeikeium and other coryneforms, Propionibacterium spp., and certain yeasts (e.g., Pityrosporum spp.) that can withstand these hostile conditions and compete successfully for binding sites and nutrients to establish a permanent and intimate attachment to the epidermis [16].

Many of the resident bacteria also elaborate toxins that inhibit other closely related microorganisms, allowing individual species to retain their foothold and consolidate their territory. Resident species also grow as biofilms, which consist of microcolonies enmeshed in a glycocalyx, rather than the planktonic growth found in laboratory cultures. Thus each microbial consortium possesses a boundary and exists as a distinct unit separate from its neighbors, rather like the various plants found in a garden.

\subsection{Erosion of the skin integument}

The effectiveness of the skin as a defense barrier can be eroded in a variety of ways. Topical antibiotics and those secreted in sweat will disturb the balance within the resident commensal flora, leaving the surface vulnerable to colonization by exogenous potential pathogens such as the gram-negative bacteria. Antibiotics will also exert selective pressure on the resident flora, causing 
resistance to emerge, as has been observed during treatment with ciprofloxacin because the drug is secreted with sweat [17]. Chemotherapy and irradiation can bring about radical changes in the normal skin by interrupting normal cell replacement, resulting in hair loss, dryness, and loss of sweat production. In addition, steroids also can exert a profound effect on sebum secretions. When the skin is broken, the release of fibronectin is thought to assist colonization with Staphylococcus aureus, and other changes facilitate colonization with gram-negative bacilli such as Acinetobacter baumanii and enterobacteria. Cutaneous infection results from the loss of integrity and reduced local immunity of the skin as well as disturbances within the resident flora. Abraded skin and the associated exudates and minor breaches in the integument can lead to local infection as well as provide a reservoir that assists further spread to other body surfaces, including the oral cavity. When the balance is lost between the host defenses and resident commensal flora around the hair follicles, they can become inflamed and necrotic, forming a potential nidus of infection.

\subsection{Impact of intravenous catheters on the integrity of the skin}

Cutaneous infections in the immunocompromised patient can also develop from needle punctures, but the insertion of catheters provides the single most effective means of breaching the natural protective barrier of the skin and creating access for microorganisms to both the stratum corneum and the bloodstream. Intravenous catheters are often essential for the successful management of immunocompromised patients because they provide ready and safe access to the bloodstream with minimal trauma and discomfort. With good technique, the complications resulting from inserting indwelling catheters, such as the Hickman device, are minimal. However, the devices frequently become colonized with organisms that have a predilection for hydrophobic surfaces and a proclivity to form biofilms. Indeed, intraluminal colonization by coagulase-negative staphylococci may be unavoidable because these organisms can be recovered from almost all devices $[18,19]$. These staphylococci are commonly resistant to tobramycin, trimethoprim, and methicillin, and may also be resistant to ciprofloxacin [20].

Unless the catheter ends in an implanted port, skin commensals have open access directly into the bloodstream depending upon how frequently it is used [21]. This is thought to be the common route of infection by other, normally minor, residents of the skin flora such as Corynebacterium urealyticum that are given a selective advantage by antimicrobial agents [22]. Unusual saprophytic bacteria, such as Comomonas acidovorans [23], Ochrobactrum anthropi, and Agrobacterium spp. [24], as well as the more common and familiar species of gram-negative bacilli, including Pseudomonas aeruginosa, that are found in aqueous environments, also gain access this way and have the ability to attach to the silicone used to make catheters and to grow in biofilms, producing copious amounts of slime. Moreover, when such organisms colonize the 
device, antibiotic treatment rarely achieves a complete cure, necessitating removal of the catheter.

Infections related to the external surface of the catheter, particularly exit-site infections and tunnel infections, occur much less frequently than does intraluminal colonization and tend to involve other resident grampositive bacteria, including Corynebacterium jeikeium and Stomatococcus mucilaginosus, and occasionally some gram-negative bacilli (Acinetobacter spp. and Stenotrophomonas (Xanthomonas) maltophilia), which have established colonization beforehand. The catheter is also a portal of entry for fungi, including Candida parapsilosis [25] and other Candida [26,27] and for molds such as Aspergillus and Mucor.

Infections associated with intravenous catheters more often represent colonization of the lumen, which gives rise to bacteremia. While many, if not most, cases of intraluminal colonization do not represent a threat to the patient, metastatic infection can occur when $S$. aureus, Candida spp., and gramnegative bacilli are involved. Persistent colonization with coagulase-negative staphylococci or Corynebacterium jeikeium often leads to repeated episodes of bacteremia, which may only be noticed when the patient experiences shaking chills, tachycardia, hypotension, and peripheral cyanosis after the line is manipulated, the classic manifestations of intraluminal colonization. Colonization of the external surface of a catheter may lead to infection of the catheter-tissue interface at the exit site, which occasionally extends along the track, causing cellulitis when a tunneled device such as the Hickman catheter is involved or phlebitis.

\section{Upper respiratory, alimentary, and genitourinary tracts}

The surface area of the upper respiratory, alimentary, and genitourinary tracts available for microbial colonization is greater than that afforded by the skin because of the folds, crypts, and villi. The surfaces of each anatomical region are also very different, ranging from the hard enamel of the teeth to the microvilli of the bowel. Extreme changes in the local environment also occur, ranging from the neutrality of the mouth to the acidity of the stomach. Moreover, both extremes of the alimentary tract are anaerobic and together contain approximately $10^{14}$ microbial cells, representing some 700 different species. The relationship between these commensals and the host are both complex and poorly understood. Nevertheless, some generalizations are possible and useful in understanding how the mucosal surfaces play their part as a first line of defense.

Two principal physical host factors influence the microbial ecology of the mucosal surfaces. Dilution of the inoculum is achieved by sneezing and coughing of microbes trapped in mucus, flushing of the mouth and esophagus by saliva, micturition, and peristalsis of the intestines. Acidity plays a crucial role both in disinfecting the stomach and in regulating the microbial milieu of the 
vagina. The upper respiratory, alimentary, and genitourinary tracts are essentially composed of epithelial cells interspersed by cells that produce the glycoproteins known as mucins. These hydrophilic substances perform various functions, including lubrication, waterproofing, and sudden changes in osmotic pressure [28]. They also contain inhibitory substances, such as lactoferrin, lysozyme, and peroxidase, as well as secretory $\operatorname{IgA}$. Mucins also appear to interfere with adherence of foreign bacteria to epithelial cells and prevent access of antigens to antibodies while allowing the biofilm or glycocalyx formed by resident bacteria to blend or fuse so that the bacteria can form a more intimate contact with the epithelial cells.

The resident flora probably play a crucial role in maintaining the integrity of this part of the integument. They compete with one another for sites of attachment and nutrients as they continually modulate the microecology. Their activity is sometimes beneficial to the human host, such as the synthesis of vitamin $\mathbf{B}_{12}$, but can also be harmful, as in the production of carcinogens from nitrates. On the whole, however, the microflora are commensals exhibiting stable symbiosis. The human host is probably immunologically tolerant to all members of resident flora because fewer than $5 \%$ of the genera have ever been implicated as opportunistic pathogens, even in the most profoundly immunosuppressed individuals. For example, even when translocation into the bloodstream occurs, the resident bacteria are poorly adapted to the environment within the body proper and only rarely establish an intracorporeal infective process.

\subsection{Resident microorganisms of the upper respiratory tract and oral cavity}

Although there are over 40 different bacterial species that reside on the epithelia of the upper respiratory tract and oral cavity, very few are capable of successful translocation into the bloodstream and fewer still of establishing disseminated infection (Table 2). In fact, during the course of a normal day, the acts of chewing and brushing the teeth may lead to transient bacteremia due to viridans streptococci; hence, their involvement in bacterial endocarditis. Most of the species capable of causing infection do so only to a limited extent, and primarily in individuals with poor oral hygiene.

\subsection{Effect of chemotherapy and irradiation on the oral cavity}

Cytotoxic chemotherapy and irradiation interrupt cell division, leading to breakdown in the integrity of the oral mucosa. The production of saliva may also be impaired, leading to a dry mouth and, if mucin is produced, may be extremely viscous and difficult to either swallow or expectorate. Periodontal disease may be exacerbated and minor oral cuts and abrasions may become inflamed or ulcerated. The nonkeratinized surfaces of the mouth, including the dorsal surface of the tongue, the roof of the mouth, and the buccal mucosa, may become erythematous, inflamed, and edematous, limiting the intake of 
Table 2. Resident flora of the upper respiratory tract and oral cavity

\begin{tabular}{|c|c|c|}
\hline Major group & Genus & Opportunistic pathogens \\
\hline Gram-positive cocci & $\begin{array}{l}\text { Micrococcus spp. } \\
\text { Staphylococcus spp. } \\
\text { Stomatococcus spp. } \\
\text { Streptococcus spp. nonhemolytic group } \\
\text { Streptococcus spp. viridans group }\end{array}$ & $\begin{array}{l}\text { S. epidermidis } \\
\text { S. mucilaginosus } \\
\text { S. milleri } \\
\text { S. oralis, S. mitis }\end{array}$ \\
\hline Gram-positive bacilli & $\begin{array}{l}\text { Actinomyces spp. } \\
\text { Arachnia } \text { spp. } \\
\text { Bacillus } \text { spp. } \\
\text { Bacterionema spp. } \\
\text { Bifidobacterium } \mathrm{spp} . \\
\text { Clostridium } \mathrm{spp} . \\
\text { Corynebacterium } \mathrm{spp} . \\
\text { Eubacterium } \mathrm{spp} . \\
\text { Lactobacillus } \mathrm{spp} . \\
\text { Propionibacterium spp. } \\
\text { Rothia } \text { spp. }\end{array}$ & C. sporogenes \\
\hline Gram-negative cocci & $\begin{array}{l}\text { Moraxella spp. } \\
\text { Neisseria spp. } \\
\text { Veillonella spp. }\end{array}$ & M. catarrhalis \\
\hline Gram-negative bacilli & $\begin{array}{l}\text { Actinobacillus spp. } \\
\text { Capnocytophaga spp. } \\
\text { Eikonella spp. } \\
\text { Fusobacterium spp. } \\
\text { Haemophilus spp. } \\
\text { Leptotrichia spp. } \\
\text { Prevotella spp. } \\
\text { Selenomonas spp. } \\
\text { Wolinella spp. }\end{array}$ & $\begin{array}{l}\text { A. actinomycetemcomitans } \\
\text { C. ochracea } \\
\text { E. corrodens } \\
\text { F. nucleatum } \\
\text { H. parainfluenzae } \\
\text { L. buccalis } \\
\text { P. melanogenicus }\end{array}$ \\
\hline Spirochetes & Treponema spp. & \\
\hline Mycoplasma & Mycoplasma spp. & M. salivarium \\
\hline Yeasts & Candida spp. & C. albicans \\
\hline
\end{tabular}

both solids and liquids [29]. This phenomenon is now generally referred to as mucositis, although some prefer the older term, stomatitis. Thus, when mucositis is present, the mouth loses its normal ability to dilute foreign bacteria. Mucositis also occurs at the same time as other manifestations of toxicity, particularly bone marrow depletion and gut toxicity, manifested by nausea, vomiting, and diarrhea. Moreover, mucosal changes normally progress to a peak severity and coincide with the nadir of bone marrow aplasia and then begin to recover as hematopoiesis returns (Figure 5) [29-32].

Exposing oral commensal flora to the antimicrobial agents used for prophylaxis and local antisepsis will inevitably select for more resistant species. Very susceptible bacteria, such as the oral Neisseria spp., will be suppressed by a wide range of antimicrobials, whereas others that are marginally susceptible to agents frequently used, such as co-trimoxazole, penicillin, and fluoroquinolones, will thrive. This partly explains why the viridans strepto- 


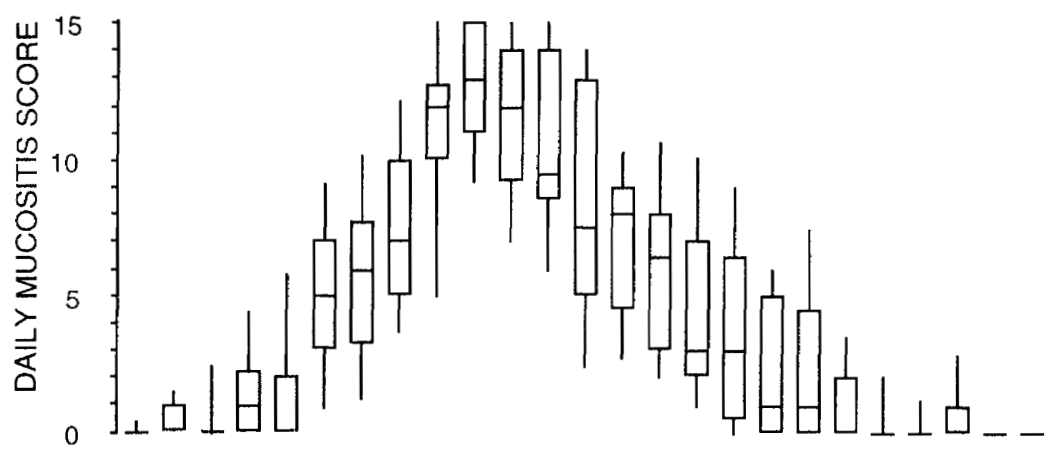

\section{Days after starting chemotherapy}

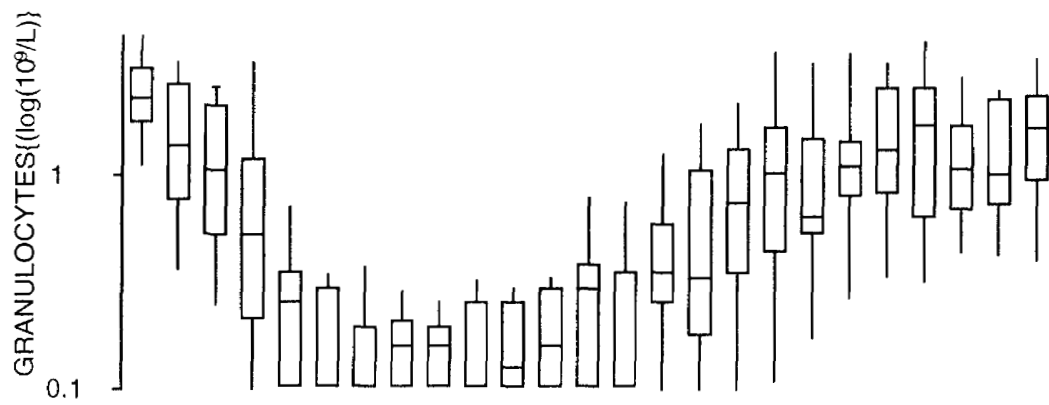

Figure 5. Mucositis. Mucositis and bone marrow aplasia, leading to profound neutropenia, are both manifestations of toxicity frequently occurring together with gut toxicity manifested by nausea, vomiting, and diarrhea. As with neutropenia, mucosal changes normally progress to a peak severity, which coincides with the nadir of bone marrow aplasia and then begins to recover as hematopoiesis returns.

cocci have become one of the most frequent causes of bacteremia in neutropenic patients who have undergone cytostatic chemotherapy for leukemia or who have received a bone marrow transplant [33], although the chemotherapeutic agents may be a more important factor, especially when it induces severe mucosal damage [34]. One particular viridans streptococcus species, Streptococcus mitis, many of which are actually S. oralis (formerly S. sanguis II) [35], is causing concern because its appearance in the bloodstream following treatment with high-dose cytarabine is associated with the sepsis syndrome and the adult respiratory distress syndrome (ARDS).

Bacteremia due to other unusual oral commensals, such as Stomatococcus mucilaginosus, Capnocytophaga spp., and Leptotrichia buccalis, are likely to be selected for by quinolones because they are also only marginally susceptible. In addition, gingivitis as the source of bacteremia due to $S$. epidermidis has been reported [36]. Similar risk factors are associated with the development of bacteremia following chemotherapy due to members of the 
Streptococcus milleri group [37]. The chlorhexidine mouthwashes used to minimize infective complications arising from the oral toxicity induced by chemotherapy also influence the microflora $[30,38,39]$. The oral flora may also change as a direct result of chemotherapy [40], and it is likely that more intensive conditioning regimens will aggravate mucositis, leading to a commensurate increase in the number of unusual bacteria.

Use of the growth factors, granulocyte-colony stimulating factor (G-CSF) and granulocyte macrophage-colony stimulating factor (GM-CSF) [41,42] does not appear to have any influence on mucositis [43]. Therefore, neutropenic patients will continue to experience varying degrees of mucosal damage depending upon the nature of their therapy because some chemotherapeutic agents (e.g., methotrexate, high doses of cytarabine and melphalan) produce extensive damage, often with the production of thick mucus $[44,45]$. Mucositis can also be particularly severe when anthracyclines are combined with total body irradiation and cyclophosphamide to condition patients for an allogeneic transplant [46]. Fortunately, the morbidity associated with gram-positive infections is usually mild and the attributable mortality is negligible [47-52].

The lung appears to be particularly vulnerable to damage by cytotoxic chemotherapy and irradiation, and is exquisitely susceptible to infection. Immunopathological reactions mediated by the pulmonary macrophages that survive chemotherapy can lead to various other syndromes, including respiratory distress. Pulmonary hemorrhage as a result of profound thrombocytopenia further imperils the lung, increasing the risk of infection. However, the risk of invasion and dissemination is high when the integrity of the mucosa is impaired and the ecology of resident flora is disturbed, and an exogenous microorganism such as a gram-negative bacillus or other potential pathogen establishes colonization. Resident flora such as Candida spp. can result in superficial infection, often as a consequence of reactivation of herpes simplex virus [53,54]. Clinically, the presence of pseudomembranes over the ulcerated tissue can initiate local invasion and progressive spread to the esophagus and gastrointestinal tract, resulting in disseminated candidiasis. Aspiration and inhalation of spores and hyphal elements of Aspergillus spp. and other molds permits colonization of the sinuses and bronchial tree, which may extend into the alveolar spaces, resulting in invasive disease that is often fatal.

\section{Microflora of the intestinal tract}

The alimentary tract is the major reservoir of gram-negative bacilli, which are either endogenous (e.g., Escherichia coli) or have been acquired by ingestion (e.g., Klebsiella pneumoniae and Pseudomonas aeruginosa) [55-57]. Normally, the alimentary tract flora contains in excess of $10^{14}$ microorganisms, amounting to several grams, but only very few species are capable of establishing infec- 
Table 3. Resident flora of the lower alimentary tract

\begin{tabular}{|c|c|c|}
\hline Major group & Genus & Opportunistic pathogens \\
\hline Gram-negative anaerobic bacilli & $\begin{array}{l}\text { Bacteroides spp. } \\
\text { Desulfomonas spp. } \\
\text { Leptotrichia } \text { spp. } \\
\text { Fusobacterium spp. } \\
\text { Butyrvibrio } \text { spp. } \\
\text { Sucinimonas spp. } \\
\text { Vibrio spp. }\end{array}$ & $\begin{array}{l}\text { B. fragilis } \\
\text { L. buccalis } \\
\text { F. nucleatum }\end{array}$ \\
\hline $\begin{array}{l}\text { Gram-negative facultatively } \\
\text { anaerobic bacilli }\end{array}$ & $\begin{array}{l}\text { Escherichia spp. } \\
\text { Citrobacter spp. } \\
\text { Klebsiella } \text { spp. } \\
\text { Enterobacter spp. } \\
\text { Morganella } \text { spp. } \\
\text { Proteus spp. }\end{array}$ & $\begin{array}{l}\text { E. coli } \\
\text { C. freundii } \\
\text { K. pneumoniae } \\
\text { E. cloacae } \\
\text { M. morganii } \\
\text { P. mirabilis }\end{array}$ \\
\hline $\begin{array}{l}\text { Gram-positive facultatively } \\
\text { anaerobic bacilli }\end{array}$ & Lactobacillus spp. & L. rhamnosus \\
\hline Gram-positive anaerobic bacilli & $\begin{array}{l}\text { Bifidobacterium spp. } \\
\text { Clostridium } \text { spp. } \\
\text { Eubacterium } \text { spp. } \\
\text { Lachnospira spp. } \\
\text { Propionibacterium spp. }\end{array}$ & $\begin{array}{l}\text { C. tertium, C. difficile, } \\
\text { C. sporogenes } \\
\text { P. acne }\end{array}$ \\
\hline $\begin{array}{l}\text { Gram-positive facultatively } \\
\text { anaerobic cocci }\end{array}$ & $\begin{array}{l}\text { Enterococcus spp. } \\
\text { Staphylococcus spp. } \\
\text { Streptococcus spp. }\end{array}$ & $\begin{array}{l}\text { E. faecalis, E. faecium } \\
\text { S. epidermidis } \\
\text { S. milleri, S. mitis, S. oralis, } \\
\quad \text { S. bovis }\end{array}$ \\
\hline Gram-positive anaerobic cocci & $\begin{array}{l}\text { Peptococcus spp. } \\
\text { Peptostreptococcus spp. } \\
\text { Acidaminococcus } \text { spp. } \\
\text { Megasphaera spp. }\end{array}$ & \\
\hline Gram-positive anaerobic cocci & $\begin{array}{l}\text { Ruminococcus spp. } \\
\text { Sarcina } \text { spp. } \\
\text { Veillonella } \text { spp. } \\
\text { Coprococcus spp. } \\
\text { Gemella } \text { spp. }\end{array}$ & \\
\hline Yeasts & Candida spp. & $\begin{array}{l}\text { C. albicans, C. glabrata, C. krusei, } \\
\text { C. lusitania }\end{array}$ \\
\hline
\end{tabular}

tion, even in the most profoundly immunosuppressed patient. Most of the microbial flora is densely distributed around the surfaces of the oral cavity and the large bowel, where scores of different microorganisms, including spirochetes, spore formers, bacilli, and cocci, compete for the available surfaces and nutrients. Anaerobes predominate and play a crucial role in maintaining a healthy commensal flora, preventing the establishment of exogenous or allochthonous organisms, which is known as colonization resistance [58,59]. The integrity of the mucosa, the production of saliva and mucus, peristalsis, gastric $\mathrm{pH}$, bile acids, digestive enzymes, and the levels of secretory $\operatorname{IgA}$ also play an important role in maintaining colonization resistance [60]. 


\subsection{Impact of antimicrobial agents on colonization resistance of the alimentary tract}

Exposure to antimicrobial agents is one of the most effective means for destroying colonization resistance, as is manifest by fungal overgrowth, and increases in the enterococcal populations [61-63]. The most likely contributors to colonization resistance, the gram-positive nonsporing, lactic acid-producing bacilli, particularly bifidobacteria, are particularly susceptible to antibiotics known to impair colonization resistance, including the penicillins, rifamycin, clindamycin, erythromycin, bacitracin, and vancomycin [60,64-68]. Some cephalosporins are also detrimental to colonization resistance, whereas other $\beta$-lactams (e.g., meropenem) and the quinolones have been declared "friendly" [61,68-73]. Some drugs such as aztreonam and imipenem only appear "friendly" because they are inactivated by feces [63,74], whereas under the circumstance of diarrhea, parenteral feeding, and gut toxicity, normal stool is no longer produced so these agents may remain sufficiently active to destroy what remains of the colonization resistance. Initially co-trimoxazole was thought to be neutral $[60,68,75-79]$, but recent evidence suggests otherwise [80]. Individual antibiotics that appear to spare colonization resistance, such as ceftazidime and piperacillin, might have a marked impact when given in combination, leading to an increase in both Clostridium difficile as well as yeasts [81]. These bacteria can lead to enterocolitis, which responds to treatment with metronidazole or oral vancomycin, but the latter may select for resistant bacteria such as Enterococcus faecium and Lactobacillus rhamnosus [82]. The widespread use of fluoroquinolones for prophylaxis has led to the emergence of resistance among the Escherichia coli, which are indigenous to the bowel [83-86].

\subsection{Effect of chemotherapy and irradiation on the intestinal tract}

One of the most important consequence of the loss of colonization resistance is that cell surfaces become vacant, allowing some exogenous bacteria such as $P$. aeruginosa to establish residence, leading to chronic colonization, with the attendant risks of invasion and systemic dissemination. The ecology of the bowel flora is also altered markedly by diarrhea induced by treatment with certain chemotherapy [87], graft-versus-host disease [88], and total body irradiation [89]. When severe chemotherapy-induced mucositis extends to the cecum, typhlitis or neutropenic enterocolitis, can occur and the recovery of Clostridium septicum from the blood confirms the diagnosis [90]. Gut permeability also increases following conditioning therapy for bone marrow transplant [91]. Agents used either for the treatment of neoplasms or supportive care may even exert an influence on gut and oral flora, either alone or in combination.

Some chemotherapeutic agents have been shown to have antibacterial activity and even to enhance the effects of antimicrobial agents [92-97]. The 
antifungal, miconazole, is also inhibitory to gram-positive bacteria [98]. Gut motility is reduced during parenteral nutrition due to the low amounts of fiber and reduced microbial biomass, which result in dilute feces. When the gut fails to function normally, the protective "anaerobic wallpaper" may still be intact but will be unusually fragile to the effect of antimicrobial agents. Thus, unless placed in a degree of isolation and supplied with low-microbial content diets, patients will be vulnerable to acquiring other gram-negative bacilli from the environment [55-57].

\section{Platelets}

The protective role of platelets [99] in normal individuals is often underestimated but becomes obvious during treatment for a malignant disease (see Figure 2). Thrombocytopenia is an almost inevitable repercussion of intensive chemotherapy and irradiation, but a decreased function of thrombocytes is a similar matter of concern. Such a thrombocytopathy is either disease related or caused by concurrent medication (Table 4). The consequences for both an increased susceptibility to infection and a decreased capacity to repair damaged tissues can be considerable and may have an impact on the eventual outcome of a treatment episode. Thrombocytopenia also appears to be an independent risk factor for bacteremia [100], and the incidence of major hemorrhages at autopsy of patients who die with or from an infection is striking.

\section{Granulocytopenia}

Under normal circumstances the proliferation of neutrophil precursors is regulated by hematopoietic growth factors such as interleukin-3, GM-CSF, and G-CSF. Starting from a pluripotent stem cell, it takes approximately 6 days to

Table 4. Causes and sequelae of thrombocytopenia and thrombocytopathy

\begin{tabular}{ll}
\hline $\begin{array}{l}\text { Causes of thrombocytopenia } \\
\text { Disease related } \\
\text { Treatment related }\end{array}$ & $\begin{array}{l}\text { Leukemia and lymphoma, bone marrow metastasis } \\
\text { Causes of thrombocytopathy } \\
\text { Disease related } \\
\text { Treatment related }\end{array}$ \\
& $\begin{array}{l}\text { Leukemia and myeloma, renal insufficiency } \\
\text { Chemotherapy, } \beta \text {-lactam antibiotics, antiinflammatory drugs, } \\
\text { antihistamines, heparin }\end{array}$ \\
& $\begin{array}{l}\text { Hemorrhagic lesions facilitate growth of microorganisms } \\
\text { and interfere with organ function } \\
\text { Decrease of platelet-derived growth factor, epidermal cell } \\
\text { growth factor, endothelial cell growth factor, fibronectin } \\
\text { (diminished adhesion), P-selectin (diminished } \\
\text { transmigration) }\end{array}$ \\
\hline
\end{tabular}


form metamyelocytes by sequential divisions and another 6 days to mature into polymorphonuclear granulocytes [101]. Approximately $90 \%$ of the total population of neutrophils resides in the bone marrow, only to be released into the circulation upon an inflammatory stimulus. Neutrophils that enter the bloodstream are distributed over two compartments of equal size in dynamic equilibrium: a free circulating pool of neutrophils and the marginating pool, consisting of neutrophils that adhere loosely to the vascular endothelium. The size of these respective pools is under the influence of several factors.

Adherence of neutrophils to endothelial cells is mediated by a number of adhesion molecules on neutrophils, which are induced by factors such as complement factor C5a, which acts as a ligand. Likewise, there is a whole series of adhesion molecules on the endothelial cells themselves, with cytokines such as interleukin- 1 and tumor necrosis factor- $\alpha$ being important inducers of these molecules [1]. Other inflammatory impulses and glucocorticosteroids are also potent inhibitors of margination. Circulating neutrophils disappear after approximately 6 hours in blood, whereas they survive 1-3 days in tissues.

During an acute inflammatory reaction, an increase in neutrophils, sometimes accompanied by eosinophils and followed by macrophages, can be seen at the site of inflammation. The formation of this inflammatory exudate is the result of activation of several humoral factors, such as cytokines, prostaglandins, and complement, which enhance the blood flow and increase vascular permeability. This occurs in conjunction with chemotactic activity, which results from other soluble factors, especially $\mathrm{C} 5 \mathrm{a}$, leukotriene $\mathrm{B}$, interleukin-8, and bacterial products. In the peripheral blood, granulocytosis evolves as a consequence of the release of the marrow reserve and increased granulocytopoiesis on stimulation by factors such as interleukin-1. However, the mere presence of granulocytes at the site of an infection is meaningless if they are not able to execute their normal functions. Phagocytosis, a Fc- and C3b receptor-mediated process with $\mathrm{IgG} 1, \mathrm{IgG} 3$, and $\mathrm{C} 3 \mathrm{~b}$ as ligands or opsonins, results in the uptake of particles larger than $1 \mu \mathrm{m}$ via pseudopods until they enclose in a vacuole (phagosome). The rate of ingestion by neutrophils is impressive in comparison with that of other phagocytes.

As soon as the particles, with or without opsonins, make contact with the cell membrane of a granulocyte, oxidases in the membrane are triggered to activate oxygen-dependent microbicidal mechanisms, and superoxide, hydrogen peroxide, and hydroxyl radicals are formed. During and after ingestion, the lysosomes, which are microscopically visible as azurophilic granules, fuse with the phagosome and pour their digestive enzymes into the vacuole, a process known as degranulation. One of these lysosomal enzymes, myeloperoxidase, triggers the reaction of $\mathrm{H}_{2} \mathrm{O}_{2}$ with chloride, which results in the formation of hypochlorite, a potent microbicidal product. Usually this operation of phagocytosis and intracellular killing of microorganisms is a suicidal act for the neutrophils, leaving the remainder for consumption and enzymatic digestion by the more powerful macrophages. However, even 
macrophages may require cooperation with products from activated $\mathrm{T}$ lymphocytes for the optimal killing of some microorganisms.

The proliferation and maturation of eosinophilic precursors is under the control of interleukin-3, GM-CSF, and interleukin-5, and has a time span similar to that of neutrophils [102], whereas survival in the tissues appears to be considerably longer. Eosinophils are able to kill several parasites, largely by means of an extracellular process mediated by $\operatorname{IgE}$ and, probably, complement.

\subsection{Impairment of granulocyte function}

Virtually all cytotoxic drugs used in the treatment of malignant diseases have a dose-dependent deleterious effect on the proliferation of normal hematopoietic progenitor cells, including those of the myeloid series. After destruction of the mitotic pool by one or more cytotoxic compounds and depletion of the marrow pool reserve, granulocytopenia with a duration of days or weeks will ensue, particularly in the treatment of hematologic malignancies and following bone marrow transplant conditioning regimens. Likewise, therapeutic radiation may induce a clinically significant granulocytopenia, depending on dose rate, total dose given, irradiated area of the body, and field size. Total body irradiation, as used in bone marrow transplant procedures, is the most illustrative of the potential deleterious effects of irradiation. However, both chemotherapeutic drugs and irradiation do not only inhibit the proliferating cell pool, they also interfere with nonproliferating cells and their function (see Figure 2). In granulocytes this may result in decreased chemotaxis, diminished phagocytotic capacity, and defective intracellular killing. Glucocorticosteroids seem to enhance granulocytopoiesis and mobilize the marginal as well as marrow pool reserve, but these supposedly positive effects on the granulocytes are counterbalanced by numerous disadvantages. Indeed, these drugs restrain the accumulation of neutrophils at the site of inflammation through impaired migration - probably due to reduced adherent capacity of the granulocytes - and diminished chemotactic activity. Furthermore, they negatively influence phagocytosis and intracellular killing by neutrophils in a dose-dependent fashion, and are associated with a reduction in the number of eosinophils in the blood. Finally, many other drugs, including antibiotics, that are regularly used in cancer patients are known to interfere with the production and function of granulocytes, which also may lead to an increased susceptibility to infection.

Although they usually occur simultaneously, any substantial reduction of the number of granulocytes or qualitative defect in the phagocytic process can, in fact, make the patient prone to recurrent bacterial and fungal infections. Granulocytopenia is probably the paramount factor responsible for the increased frequency of infection in cancer patients because only one fifth of the febrile episodes occur when they are not granulocytopenic. It has been shown that an inverse correlation exists between the number of circulating 
neutrophils and lymphocytes, and the frequency of infection. Depending on the duration of neutropenia, the risk of a febrile episode varies between $30 \%$ and $80 \%$. In a study by Bodey and coworkers [103], all patients with a neutrophil count of less than 100 per $\mu \mathrm{L}$ for more than 3 weeks developed an infectious complication, and the risk for secondary infections increases proportionally with the duration of granulocytopenia. Moreover, infectionrelated mortality increased with the duration of hospitalization and the number of days of granulocytopenia.

\subsection{Diagnostic consequences of granulocytopenia}

It may be difficult to establish an unequivocal diagnosis of infection because the inflammatory response in patients without properly functioning granulocytes is muted, thereby obscuring the classic signs and symptoms of infection [104]. Of the episodes of fever associated with granulocytopenia, a definite infectious etiology can be established in about a quarter of cases on the basis of microbiological confirmation. Local infections, if detected at all, are frequently complicated by bacteremia, which accounts for more than $90 \%$ of culture-documented infections in cancer patients [105,106]. Microorganisms that cause a local infection or that colonize damaged mucosa or skin can easily gain access to the bloodstream in the absence of granulocytes. Between $40 \%$ and $70 \%$ of patients who become febrile while granulocytopenic have unexplained fevers, but nevertheless improve after treatment with broad-spectrum antibacterials, suggesting an occult bacterial source as the cause of fever. A small inoculum, sufficient to cause symptoms of infection in a patient with a defective defense mechanism, might be below the detection limit of standard blood culture techniques. Infectious complications usually arise insidiously in granulocytopenic patients with little or no inflammatory signs and without the formation of pus. Fever is often the only hallmark of a possible infection, but without prompt and appropriate treatment such infections may run a fulminant course in these patients (see Chapter 3).

After bacteria, fungi are the next most common pathogens, especially in immunosuppressed patients who have prolonged and profound granulocytopenia. Autopsy evidence of significant fungal infections can be found in one half of these patients. Most of these infections are not diagnosed or treated antemortem, but they account for $20-30 \%$ of fatal infections in patients with acute leukemia [107-109]. Besides granulocytopenia, the use of pharmacological doses of corticosteroids and indwelling catheters may also foster the development of systemic fungal infection [110] (see Chapter 6).

\section{Cellular immunity and cytokines}

Whereas humoral immunity is primarily responsible for clearing extracellular bacteria, the cellular immune system serves to eliminate intracellular patho- 
gens and virus-infected cells. Both antigen-specific and nonspecific cells contribute to the development of cellular immunity. Specific cells including T-helper $\left(\mathrm{T}_{\mathrm{H}}\right)$ and cytotoxic $\left(\mathrm{T}_{\mathrm{C}}\right) \mathrm{T}$ cells and nonspecific cells include macrophages, neutrophils, and natural killer (NK) cells.

Normal macrophages have a limited capacity for killing ingested microorganisms, and various organisms (e.g., Toxoplasma gondii, Pneumocystis carinii, Cryptococcus spp., Listeria spp., Salmonella spp., and Legionella spp.) are capable of surviving and replicating within the cell, unless the macrophage becomes activated. The activation process is complex and is primarily under the control of cytokines. Interferon (IFN)- $\gamma$, produced by NK cells and $T_{H}$ cells, is the most important player in the field, but the presence of tumor necrosis factor (TNF)- $\alpha$ is also required. The activated macrophage is characterized by morphological changes, expression of certain antigens, increased oxygen consumption, and a marked upregulation of both oxygen-dependent and nitric oxide-based microbicidal mechanisms, enabling the cell to kill intracellular pathogens.

The antigen-specific branch of cell-mediated immunity can be divided into two major categories. One category involves cytotoxic effector cells, which are able to lyse virus-infected or foreign lymphocytes and macrophages. The second category involves various subpopulations of $\mathrm{T}_{\mathrm{H}}$ cells that mediate delayed-type hypersensitivity reactions. These $\mathrm{T}$ cells can be activated following antigen recognition only when the antigen is displayed together with major histocompatibility complex (MHC) on the surface of specialized cells called antigen-presenting cells (APC). These antigen-presenting cells, mainly macrophages and dendritic cells, phagocytose the microorganism and then express a part of the antigen on their membrane, enabling $T_{H}$ cells to recognize the antigen (Figure 6). TNF- $\alpha$ and IL-12 are induced, and synergistically activate $\mathrm{NK}$ cells to produce IFN- $\gamma$. IFN $-\gamma$ serves to activate macrophage microbicidal systems, through induction of nitrate synthase and reactive oxygen metabolites.

These new insights place greater stress on the pivotal role of the NK cell in the earliest phase of the immune response and imply that activation of macrophages is not necessarily $\mathrm{T}$-cell mediated. Rather, $\mathrm{T}$ cells become involved at a later stage in the process after an average of 24 hours following contact with the antigen. At the level of the so-called naive, uncommitted $T_{\mathrm{H} 0}$ lymphocyte, IL-12 induces the maturation of $\mathrm{T}_{\mathrm{H} 0}$ cells to the $\mathrm{T}_{\mathrm{H} 1}$ phenotype, which produces IL-2 and IFN- $\gamma$. Under other circumstances, such as allergic reactions or infection with certain parasites, the naive $\mathrm{T}_{\mathrm{H} 0}$ cells differentiate into a $\mathrm{T}_{\mathrm{H} 2}$ subset, which produces an entirely different repertoire of cytokines specifically tailored to respond to the character of the insult. The $\mathrm{T}_{\mathrm{H} l}$ derived IL-2 functions in an autocrine manner to amplify the population of cytokine-producing T cells (see Figure 6). Moreover, IL-2 potentiates the effect of IL-12 and TNF$\alpha$ in stimulating NK cells to produce IFN- $\gamma$. Other cytokines that are produced by the activated $\mathrm{T}_{\mathrm{H} 1}$ cell include IL-3 and GM-CSF, which stimulate the granulocyte-monocyte lineage. IFN- $\gamma$ and macrophage-derived IL-1 induce a 


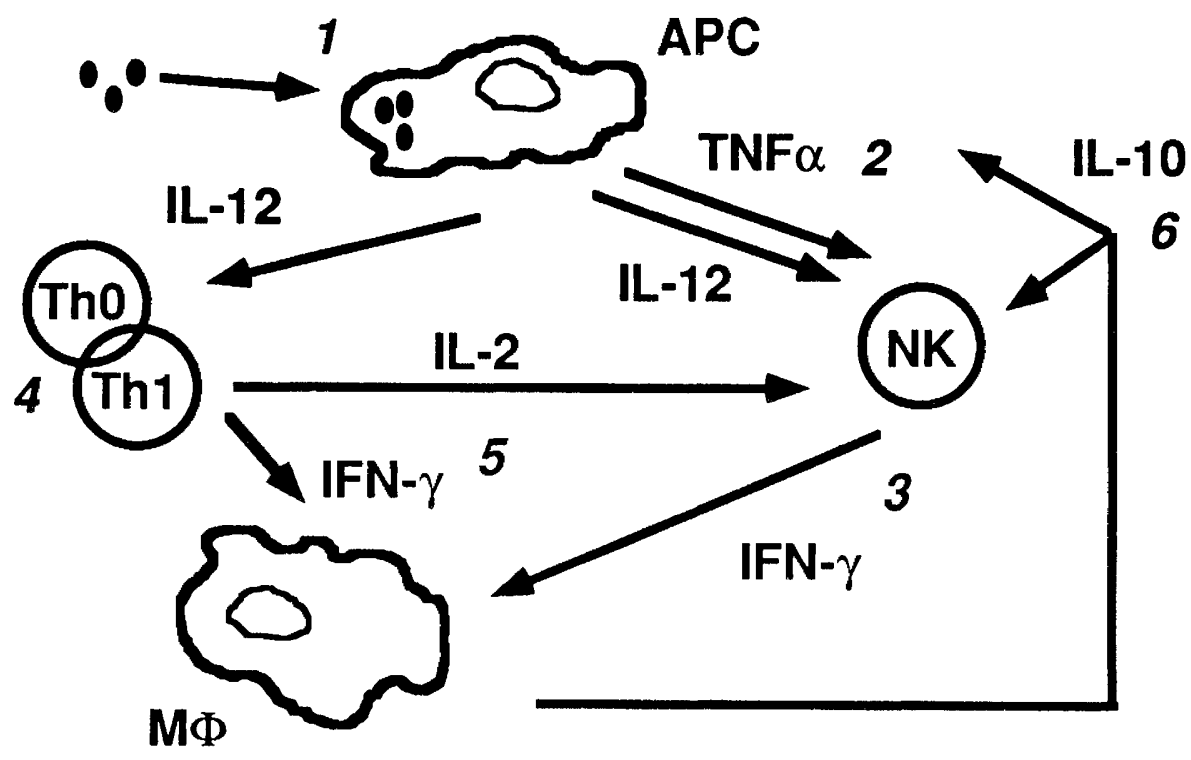

Figure 6. Development of cell-mediated immunity. (1) Microorganisms are phagocytosed by macrophages and antigen is presented. (2) Macrophages produce TNF-a and IL-12 to activate NK cells to produce IFN-g. (3) IFN-g activates microbicidal functions of macrophages. (4) IL-12 also induces naive $\mathrm{T}$-helper $\left(\mathrm{T}_{\mathrm{H} 0}\right)$ cells to differentiate into $\mathrm{T}_{\mathrm{HI}}$ cells, secreting IL-2 and IFN-g. (5) In an autocrine fashion, IL-2 stimulates T cells and also activates NK cells to produce IFN-g. (6) Macrophages begin to produce IL-10, which inhibits TNF-a, IL-12, and IFN-g production in order to terminate the process of the cellular immune response after several days.

number of changes in nearby endothelial cells, facilitating extravasation of monocytes and other nonspecific inflammatory cells. Also, the expression of cellular adhesion molecules, including ICAM, VCAM, and ELAM, is increased, and IL-8 is secreted. Together, these reactions lead to an influx of neutrophils and monocytes to the site of infection. Somewhat later, with a peak occurring 24-48 hours after the infection, macrophages begin to produce IL-10, which acts as a negative feedback by inhibiting IFN- $\gamma$ production. This effect of IL-10 is accomplished by two mechanisms: inhibition of macrophage TNF- $\alpha$ and IL-12 production, and direct suppression of IFN- $\gamma$ production by NK cells. This downmodulation of the response occurs at the time that specific $T$ cells begin to further modulate the cellular response to infection.

The importance of cell-mediated immunity in protecting the host against various intracellular pathogens is evident from the opportunistic infections occurring in various groups of cancer patients. Patients treated with prednisone or other immunosuppressive agents that specifically affect cellmediated responses may become unable to cope with intracellular pathogens such as Listeria monocytogenes, Pneumocystis carinii, or Toxoplasma gondii. The classic concept of Hodgkin's lymphoma is that of a disease associated with 
impaired cellular immunity, although delayed hypersensitivity responses are intact in the majority of untreated patients [111]. No anergy has been found in patients with stage I disease, and the incidence of cellular immune defects increases with disease stage to affect only approximately $25 \%$ of patients with stage IV disease. The defect in T-cell-mediated immunity in patients with Hodgkin's disease is probably due to an excess of T suppressor cells, which leads to increased susceptibility to varicella-zoster virus (VZV) infections, tuberculosis, cryptococcosis and, in the United States, endemic mycoses such as histoplasmosis and coccidioidomycosis. Cytotoxic treatment of patients with lymphoma that leads to severe neutropenia may render these patients at risk for severe gram-negative and other fungal infections, thereby obscuring the classic association of both Hodgkin's and non-Hodgkin's lymphoma with defects in cellular immunity.

Allogeneic bone marrow transplantation (BMT) brings about a long-lasting dysfunction of $\mathrm{T}$ and $\mathrm{B}$ cells, and the opportunistic infection due to these defects may become manifest long after transplantation and recovery from neutropenia. The most prominent example is VZV infection, which occurs in up to $50 \%$ of BMT recipients in some series. The median time of onset is 5 months after transplant. The spectrum of the disease ranges from primary infection (varicella) to localized or often disseminated herpes zoster. Prophylaxis with acyclovir is advocated in many centers for the first 9 months after transplant. Chronic graft-versus-host disease and the immunosuppressive agents used for its treatment further render these patients at risk for infection with VZV, Aspergillus spp. and Pneumocystis carinii.

\section{Humoral immunity}

The humoral branch of the immune system involves interaction of B cells with antigen and their subsequent proliferation and differentiation into antibodysecreting plasma cells. An important difference in antigen recognition by $\mathrm{T}$ cells and B cells is that the latter can recognize an antigen, whereas $T$ cells can only do so once the antigen has been phagocytosed and is presented on the surface of an antigen-presenting cell. In this way, the immune system is able to cope with invaders under a variety of different circumstances. The humoral system recognizes a plethora of bacterial or viral microorganisms as well as the soluble proteins they release. The cell-mediated system is suited to recognizing altered cells belonging to the "self", that is, infected phagocytes as well as cancer cells. Upon challenge with an antigen, immunoglobulins are produced by the humoral branch of the system and bind to the antigen. IgM is secreted early and during differentiation. Plasma cells then become committed to produce the other classes of immunoglobulin, such as $\operatorname{IgG}, \operatorname{IgA}$, $\operatorname{IgE}$, and $\operatorname{IgD}$ [1]. The specific functions of IgG and IgM include not only neutralization of the antigen, but also complement activation and opsonization. Secretory IgA, which is found on mucosal surfaces, is not an opsonin but it inhibits the 
motility of bacteria, neutralizes their toxins, and prevents their adherence to epithelial cells. Circulating IgA probably plays only a minor role in host defense.

Tuftsin is a small peptide that binds to the Fc portion of IgG and becomes involved in activating phagocytes after being released from the immunoglobulin. Two enzymes are required for this process: leukokinase, which is bound to the membranes of neutrophils and macrophages, and tuftsin endocarboxypeptidase, which is produced in the spleen. The decreased availability of functional tuftsin is one of the mechanisms that contribute to the increased risk of severe infections after a staging splenectomy in patients with malignancies. Other mechanisms include the clearance of particles that have not been opsonized by complement. The spleen plays an important role in the humoral immune response as the primary immunoglobulin response takes place there, as shown by the low concentrations of IgM found after splenectomy. Reduced concentrations of the complement factor properdin have also been found, leading to suboptimal opsonization. Functional asplenia develops in a large proportion of patients after allogeneic BMT and is also associated with increased risk for bacterial infections.

Humoral immunity is impaired in patients with malignancies, leading to decreased production of immunoglobulins, such as in chronic lymphocytic leukemia (CLL), multiple myeloma, and other lymphoproliferative disorders. Humoral immunity is generally well preserved in patients with acute lymphocytic or myelogenous leukemia. However, with intensive chemotherapy and/or progression of the disease, the capacity to produce immunoglobulins decreases. This may lead to defective opsonization of bacteria and subsequent impairment of phagocytosis by neutrophils and macrophages, adding to the quantitative effect of chemotherapy-induced neutropenia.

Although the humoral response in patients with malignant lymphomas is unimpaired, subsequent radiotherapy and chemotherapy, particularly if both treatment modalities are combined, lead to reduced antibody titers and increased susceptibility to infections with pneumococci and Haemophilus influenzae. Splenectomy potentiates the reduction of immunoglobulins by chemotherapy in these patients. Therefore, combined therapy may increase the risk of postsplenectomy bacteremia in patients with lymphoma, and, even after curing Hodgkin's disease, patients are left with a potentially lifethreatening humoral immunodeficiency, due to the effects of treatment rather than to the underlying disease itself.

Thus, the advent of more aggressive chemotherapy has changed the classic concept of specific defects of host defense mechanisms in the various types of leukemia and lymphoma. The effects of chemotherapy and radiation are now the primary factor determining the nature and depth of the defect in host defense. Likewise, the increased susceptibility to pneumococci and Haemophilus influenzae in patients with CLL or multiple myeloma may be replaced by a defect in cellular immunity and neutrophil function when these patients are being treated with glucocorticosteroids or other agents. Whether 
patients with hypogammaglobulinemia due to CLL should routinely receive intravenous immunoglobulins has been a matter of considerable debate. A cost-effectiveness analysis has suggested that indiscriminate replacement may not improve quality or length of life in this patient group, and that it is extraordinarily expensive [112]. However, such a decision analysis model cannot be applied to the individual patient who actually has suffered from recurrent bacterial infections. Therefore, it seems reasonable to institute immunoglobulin replacement in those patients who have had a documented infection with pneumococcus or Haemophilus influenzae and have decreased serum IgG concentrations.

\section{Sequence of infective events}

The sequence of risk factors (Figure 7) determines to a large extent the order of infectious events in granulocytopenic cancer patients and the types of infection. The first few days after a treatment course are dominated by profound granulocytopenia and mucosal damage, placing the patient in double jeopardy. After the first week the number of positive blood cultures gradually decreases and remains relatively constant after the fourth week. From day 10 onwards, infections related to central venous catheters occur with increasing risk, depending on the length of time that the catheter is left in place [19]. Few patients develop invasive pulmonary aspergillosis early in the course of granulocytopenia [110]. The initial period of risk of bacterial and fungal infection resolves with recovery of the granulocyte, whereafter the infectious complications are determined by the pace of reconstitution of other components of the immune system, as is illustrated in bone marrow recipients [8]. The major factors that influence immunologic reconstitution after allogeneic bone marrow transplant are graft-versus-host disease and its treatment. Cytomegalovirus, adenovirus, fungi, and protozoa all constitute major pathogens in these patients. In bone marrow transplant recipients, a third major risk period begins approximately 3 months after the procedure, at the time that chronic graft-versus-host disease develops. Sinopulmonary and cutaneous infections, probably related to the IgA deficiency and sicca syndrome, are common. Varicella zoster is the most important cutaneous infection, and pulmonary infections caused by cytomegalovirus and Pneumocystis carinii may also be encountered. Months, if not years, after successful engraftment or recovery from other very aggressive treatment, encapsulated organisms can cause rapidly fatal bacteremias and severe respiratory infections due to the lack of opsonizing antibodies.

\section{Conclusions}

It is clear from the foregoing that patients with neoplastic diseases seldom suffer impairment of a single defense mechanism. Rather, the risk of infection 


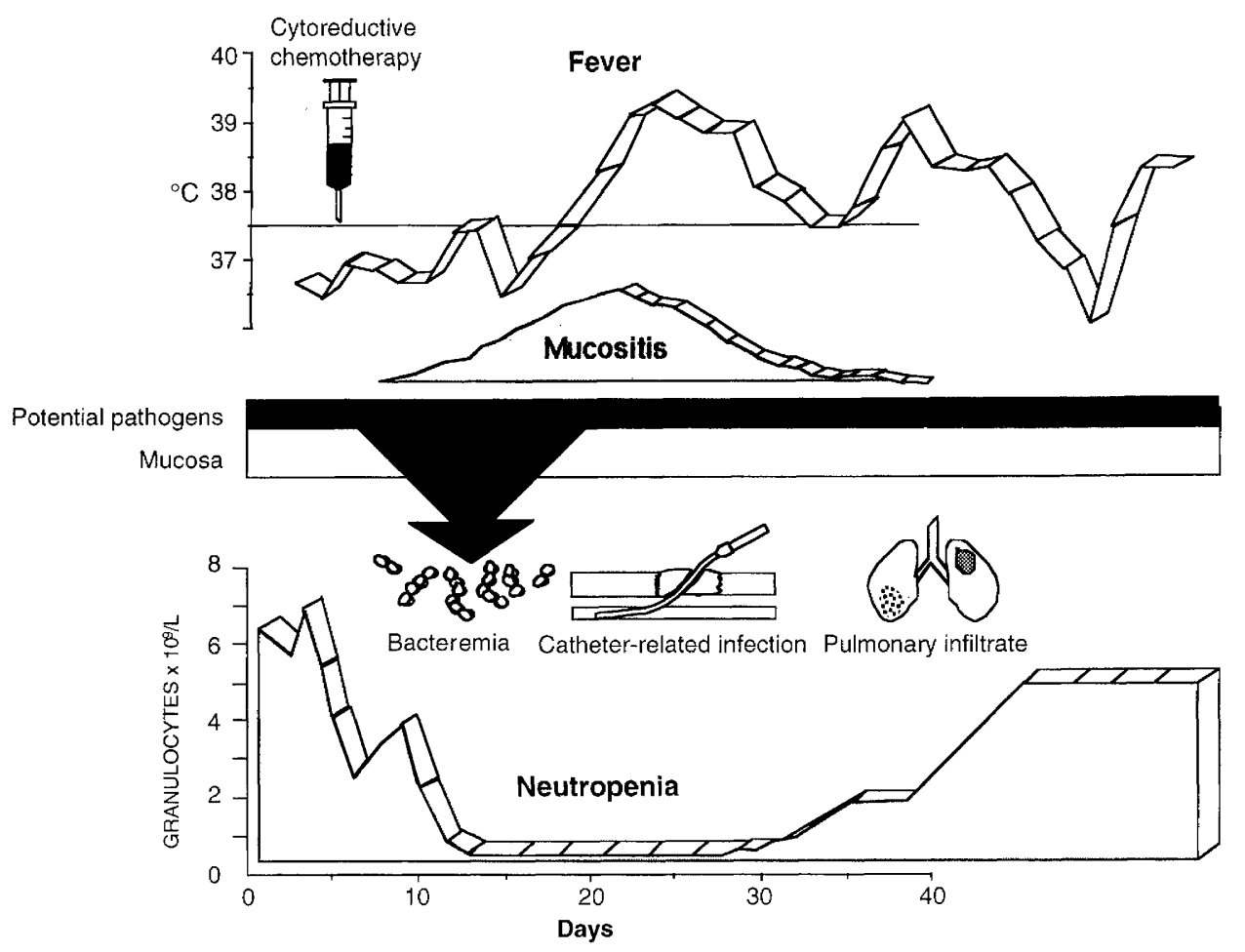

Figure 7. The sequence of events during neutropenia. Profound granulocytopenia and mucosal damage usually develop about a week after the start of cytoreductive chemotherapy. Thereafter, infectious and other complications tend to coincide with one another, placing the patient at most risk. Fever develops around a week later and, if there is bacteremia, it occurs at this time. The risk of infections related to the central venous catheter increase with the length of time that the catheter is left in place, but signs and symptoms usually manifest themselves during the first few days of fever, that is, during the third week after starting chemotherapy. Infectious complications related to the lung tend to occur a few days later, often being recognized only after 5-6 days of fever. The period of risk of bacterial and fungal infection diminishes with recovery of the granulocytes, when the clinical manifestations of tissue infections may be temporarily exacerbated before finally resolving.

is the product of an interplay between the many lines of defense, all of which can be breached simultaneously. Moreover, any attempt to confine the damage inflicted upon the host defenses by protecting only one specific line of defense (e.g., use of growth factors to stimulate hematopoiesis), is likely to be frustrated and to offer only limited benefit. What is required is a two-pronged approach involving more selective treatment, on the one hand, to avoid damaging healthy tissue and, on the other hand, strategies that prevent, or at least ameliorate, any toxicity that is unavoidable. This requires a holistic approach involving both the laboratory and the clinician in continuing to refine therapeutic regimens that are effective and in designing others to cope with the 
morbidity associated with impaired host defenses. Both are essential to successfully achieve remission of neoplastic disease and to maintain the best quality of life for the patient.

\section{References}

1. Van der Meer JWM. Defects in host defense mechanisms. In: Rubin RH, Young LS, eds. Current Approach to Infection in the Compromised Host. New York: Plenum Medical, 1994, pp. 33-66.

2. Louria DB. Introduction and epidemiology. Am J Med 1984;76:414-420.

3. Chandra RK. Nutrition, immunity and infection: Present knowledge and future directions. Lancet 1983;1:688-691.

4. Salimonu LS, Ojo-Amaize E, Williams AIO, et al. Depressed natural killer cell activity in children with protein calorie malnutrition. Clinl Immunol Immunopathol 1982;24:1-7.

5. Sugarman B. Zinc and infection. Rev Infect Dis 1983;5:137-147.

6. Craddock PR, Yawata Y, van Santen L. Acquired phagoctye dysfunction: A complication of the hypophosphatemia of parenteral hyperalimentation. N Engl J Med 1974;290:1403-1407.

7. Saltzman RL, Peterson PK. Immunodeficiency in the elderly. Rev Infect Dis 1987;9:11271139.

8. Meyers JD. Infection in bone marrow transplant recipients. Am J Med 1986;81(Suppl. 1A):27-38

9. McGeer A, Feld R. Epidemiology of infection in immunocompromised oncological patients. Baillière's Clin Infect Dis 1994;1:415-438.

10. Allen JC. The diabetic as a compromised host. In: Allen JC, ed. Infection and the Compromised Host: Clinical Correlations and Therapeutic Approaches, 2nd ed. Baltimore: Williams \& Wilkins, 1981, pp. 229-270.

11. Rubin J, Yu VL. Malignant external otitis: Insights into pathogenesis, clinical manifestations, diagnosis and therapy. Am J Med 1988;139:557-563.

12. Cech P, Stalder H, Widmann JJ, et al. Leucocyte myeloperoxidase deficiency and diabetes mellitus associated with Candida albicans liver abscess. Am J Med 1979;66:149-153.

13. Schwartz MN. Stress and the common cold. N Engl J Med 1991;325:654-656.

14. Weitzman S, Aisenberg AC. Fulminant sepsis after the successful treatment of Hodgkin's disease. Am J Med 1977;62:47-50.

15. Broome CV, Facklam RR, Fraser DW. Pneumococcal disease after pneumococcal vaccination; an alternative method to estimate the efficacy of pneumococcal vaccine. $\mathrm{N}$ Engl $\mathrm{J}$ Med 1980;303:549-552.

16. Roth RR, James WD. Microbial ecology of the skin. Ann Rev Microbiol 1988;42:441-464.

17. Kotilainen P, Nikoskelainen J, Huovinen P. Emergence of ciprofloxacin-resistant coagulasenegative staphylococcal skin flora in immunocompromised patients receiving ciprofloxacin. J Infect Dis 1990;161:41-44.

18. Weightman NC, Simpson EM, Speller DCE, Mott MG, Oakhill A. Bacteraemia related to indwelling central venous catheters: Prevention, diagnosis and treatment. Eur J Clin Microbiol Infect Dis 1988;7:125-129.

19. Raad I.I., Bodey GP. Infectious complications of indwelling vascular catheters. Clin Infect Dis 1992;15:197-210.

20. Hedin G, Hambraeus A. Multiply antibiotic-resistant Staphylococcus epidermidis in patients, staff and environment - a one-week survey in a bone marrow transplant unit. $J$ Hosp Infect 1991;17:95-106.

21. Groeger JS, Lucas AB, Thaler HT, Friedlanderklar H, Brown AE, Kiehn TE, et al. Infectious morbidity associated with long-term use of venous access devices in patients with cancer. Ann Intern Med 1993;119:1168-1174. 
22. Wood CA, Pepe R. Bacteremia in a patient with non-urinary tract infection due to Corynebacterium urealyticum. Clin Infect Dis 1994:19:367-368.

23. Castagnola E, Tasso L, Conte M, Nantron M, Barretta A, Giacchino R. Central venous catheter-related infection due to Comamonas acidovorans in a child with non-Hodgkin's lymphoma. Clin Infect Dis 1994;19:559-560.

24. Alnor D, Frimodt-Moller N, Espersen F, Frederiksen W. Infections with the unusual human pathogens Agrobacterium species and Ochrobactrum anthropi. Clin Infect Dis 1994;18:914920 .

25. Weems JJ. Candida parapsilosis: Epidemiology, pathogenicity, clinical manifestations and antibiotic susceptibility. Clin Infect Dis 1992;14:756-766.

26. Lecciones JA, Lee JW, Navarro EE, Witesby FG, Marshall D, Steinberg SM, et al. Vascular catheter-associated fungemia in patients with cancer: Analysis of 155 episodes. Clin Infect Dis $1992 ; 14: 875-883$.

27. Morrison VA, Haake RJ, Weisdorf DJ. The spectrum of non-candida fungal infections following bone marrow transplantation. Medicine 1993;72:78-89.

28. McNab PC, Tomasi TB. Host defense mechanisms at mucosal surfaces. Ann Rev Microbiol 1981:35:477-496.

29. Kolbinson DA, Schubert MM, Fluornoy N, Truelove EL. Early oral changes following bone marrow transplantation. Oral Surg, Oral Med Oral Pathol 1988;66:130-138.

30. Weisdorf DJ, Bostrom B, Raether D, Mattingly M, Walker P, Pihlstrom B, et al. Oropharyngeal mucositis complicating bone marrow transplantation: Prognostic factors and the effect of chlorhexidine mouth rinse. Bone Marrow Transplant 1989;4:89-95.

31. Donnelly JP, Muus P, Schattenberg A, Dewitte T, Horrevorts A, De Pauw BE. A scheme for daily monitoring of oral mucositis in allogeneic BMT recipients. Bone Marrow Transplant 1992;9:409-413.

32. Rocke LK, Loprinzi CL, Lee JK, Kunselman SJ, Iverson RK, Finck G, et al. A randomized clinical trial of two different durations of oral cryotherapy for prevention of 5-fluorouracil related stomatitis. Cancer 1993;72:2234-2238.

33. Bochud PY, Calandra T, Francioli P. Bacteremia due to viridans streptococci in neutropenic patients: A review. Am J Med 1994;97:256-264.

34. Donnelly JP, Dompeling EC, Meis JF, De Pauw BE. Bacteremia due to oral viridans streptococci in neutropenic patients with cancer: Cytostatics are a more important risk factor than antibacterial prophylaxis. Clin Infect Dis 1995;20:469-470.

35. Beighton D, Carr AD, Oppenheim BA. Identification of viridans streptococci associated with bacteraemia in neutropenic cancer patients. J Med Microbiol 1994;40:202-204.

36. Lina B, Forey F, Troncy J, Greenland T. Fleurette J, Etienne J. Oral source of Staphylococcus epidermidis septicemia in a neutropenic patient. Eur $\mathbf{J}$ Clin Microbiol Infect Dis 1994:13:773-774.

37. Jacobs JA, Pietersen HG, Stobberingh EE, Soeters PB. Bacteremia involving the "Streptococcus milleri" group: Analysis of 19 cases. Clin Infect Dis 1994;19:704-713.

38. Ferretti GA, Ash RC, Brown AT, Largent BM, Kaplan A, Lillich TT. Chlorhexidine for prophylaxis against oral infections and associated complications in patients receiving bone marrow transplants. JADA 1987:114:461-467.

39. Meurman $\mathrm{JH}$, Laine $\mathrm{P}$, Murtomaa $\mathrm{H}$, Lindqvist $\mathrm{C}$, Torkko $\mathrm{H}$, Teerenhovi L, et al. Effect of antiseptic mouthwashes on some clinical and microbiological findings in the mouths of lymphoma patients receiving cytostatic drugs. J Clin Periodont 1991;18:587591.

40. Bergmann OJ. Alterations in oral microflora and pathogenesis of acute oral infections during remission-induction therapy in patients with acute myeloid leukaemia. Scand J Infect Dis 1991:23:355-366.

41. Schuster MW. Granulocyte-macrophage colony-stimulating factor (GM-CSF) - what role in bone marrow transplantation. Infection 1992;20(Suppl. 2):S95-S99.

42. Bronchud M. Can hematopoietic growth factors be used to improve the success of cytotoxic chemotherapy. Anti-Cancer Drugs 1993;4:127-139. 
43. De Witte T, Van Der Lely N, Muus P, Donnelly JP, Schattenberg T. Recombinant human granulocyte macrophage colony stimulating factor (rhGM-CSF) accelerates bone marrow recovery after allogeneic $\mathrm{T}$-cell depleted bone marrow transplantation. L'Ospedale Maggiore 1993;87:42-46.

44. McGuire DB, Altomonte V, Peterson DE, Wingard JR, Jones RJ, Grochow LB. Patterns of mucositis and pain in patients receiving preparative chemotherapy and bone marrow transplantation. Oncol Nursing Forum 1993:20:1493-1502.

45. Sable CA, Donowitz GR. Infections in bone marrow transplant recipients. Clin Infect Dis 1994;18:273-284.

46. Raemaekers J, De Witte T, Schattenberg A, Van Der Lely N. Prevention of leukaemic relapse after transplantation with lymphocyte-depleted marrow by intensification of the conditioning regimen with a 6-day continuous infusion of anthracyclines. Bone Marrow Transplant 1989:4:167-171.

47. Rubin M, Hathorn JW, Marshall D, Gress J, Steinberg SM, Pizzo PA. Gram-positive infections and the use of vancomycin in 550 episodes of fever and neutropenia. Ann Intern Med 1988:108:30-35.

48. The EORTC International Antimicrobial Therapy Cooperative Group. Gram-positive bacteraemia in granulocytopenic cancer patients. Eur J Cancer 1990;26:569-574.

49. The EORTC International Antimicrobial Therapy Cooperative Group and National Cancer Institute of Canada. Vancomycin added to empirical combination antibiotic therapy for fever in granulocytopenic cancer patients. J Infect Dis 1991;163:951-958.

50. Awada A, Van Der Auwera P, Meunier F, Daneau D, Klastersky J. Streptococcal and enterococcal bacteremia in patients with cancer. Clin Infect Dis 1992;15:33-48.

51. Devaux Y, Archimbaud E, Guyotat D, Plotton C, Maupas J, Fleurette J, et al. Streptococcal bacteremia in neutropenic adult patients. Nouv Rev Fr Hematol 1992;34:191-195.

52. Menichetti F. Gram-positive infections in neutropenic patients - glycopeptide antibiotic choice. J Antimicrob Chemother 1992;29:461-462.

53. Beattie G, Whelan J, Cassidy J, Milne L, Burns S, Leonard R. Herpes simplex virus, Candida albicans and mouth ulcers in neutropenic patients with non-haematological malignancy. Cancer Chemother Pharmacol 1989:25:75-76.

54. Bergmann OJ. Oral infections in haematological patients - pathogenesis and clinical significance. Danish Med Bull 1992;39:15-29.

55. Van der Waaij D. The colonization resistance of the digestive tract of man and animals. In: Clinical and Experimental Gnotobiotics. New York: Gustav Fischer Verlag, 1979.

56. Schimpff SC. Infection prevention during profound granulocytopenia: New approaches to alimentary canal microbial suppression. Ann Intern Med 1980;93:358-361.

57. Young LS. Antimicrobial prophylaxis against infection in neutropenic patients. J Infect Dis 1983;147:611-614.

58. Van der Waaij D. The ecology of the human intestine and its consequences for overgrowth by pathogens such as Clostridium difficile. Ann Rev Microbiol 1989;43:69-87.

59. Vollaard EJ, Clasener HAL. Colonization resistance. Antimicrob Agents Chemother 1994;38:409-414.

60. Van der Waaij D. Effect of antibiotics on colonization resistance. In: Medical Microbiology. London: Academic Press, 1984, pp. 227-237.

61. Louie TJ, Chubb H, Bow EJ, Conly JM, Harding GKM, Rayner E, et al. Preservation of colonization resistance parameters during empiric therapy with aztreonam in febrile neutropenic patient. Rev Infect Dis 1985;7:S747-S761.

62. Meijer-Severs GJ, Van Santen E. Short-chain fatty acids and succinate in feces of healthy human volunteers and their correlation with anaerobic cultural counts. J Gastroenterol 1987;22:672-676.

63. Welling GW, Groen G. Inactivation of aztreonam by faecal supernatants of healthy volunteers as determined by HPLC. J Antimicrob Chemother 1989;24:805-810.

64. Dietrich M, Rasche H, Rommel K, Hochapfel G. Antimicrobial therapy as a part of the decontamination procedures for patients with acute leukemia. Eur J Cancer 1973;9:443-447. 
65. Bender JF, Schimpff SC, Young VM, Fortner CL, Brouillet MD, Love LJ, et al. Role of vancomycin as a component of oral nonabsorbable antibiotics for microbial suppression in leukemic patient. Antimicrob Agents Chemother 1979;15:455-460.

66. Pizzo PA, Robichaud KJ, Edwards BK, Schumaker C, Kramer BS, Johnson AJ. Oral antibiotic prophylaxis in patients with cancer: A double-blind randomized placebocontrolled trial. J Pediatr 1983;102:125-133.

67. Walsh TJ, Schimpff SC. Prevention of infection among patients with cancer. Eur J Cancer Clinical Oncology 1983;19:1333-1344.

68. Nord CE, Kager L, Heimdahl A. Impact of antimicrobial agents on the gastrointestinal microflora and the risk of infections. Am J Med 1984;15:99-106.

69. Jones PG, Bodey GP, Swabb EA, Rosenbaum B. Effect of aztreonam on throat and stool flora of cancer patients. Antimicrob Agents Chemother 1984;26:941-943.

70. Rozenberg-Arska M, Dekker AW, Verhoef J. Ciprofloxacin for selective decontamination of the alimentary tract in patients with acute leukemia during remission induction treatment: The effect on fecal flora. J Infect Dis 1985;152:104-107.

71. Jones RN, Barry AL, Thornsberry C. In-vitro studies of meropenem. J Antimicrob Chemother 1989;24(Suppl. A):9-29.

72. Vollaard EJ, Clasener HAL, Janssen AJHM. The contribution of Escherichia coli to microbial colonization resistance. J Antimicrob Chemother 1990;26:411-418.

73. Vollaard EJ, Clasener HAL, Janssen AJHM. Decontamination of the bowel by intravenous administration of pefloxacin. J Antimicrob Chemother 1990;26:847-852.

74. Welling GW, Slootmakervandermeulen C, Jansen GJ. Inactivation of imipenem by faecal fractions from human volunteers and the effect of clavulanate and cilastatin. J Antimicrob Chemother 1993;31:617-619.

75. Van der Waaij D, Hofstra H, Wiegersma N. Effect of $\beta$-lactam antibiotics on the resistance of the digestive tract of mice to colonization. J Infect Dis 1982;146:417-422.

76. Wiegersma N, Jansen G, Van Der Waaij D. Effect of twelve antimicrobial drugs on the colonization resistance of the digestive tract of mice and on endogenous potentially pathogenic bacteria. J Hygiene (Cambridge) 1982;88:221-230.

77. Clasener HA, Vollaard EJ, van Saene HK. Long-term prophylaxis of infection by selective decontamination in leukopenia and in mechanical ventilation. Rev Infect Dis 1987;9:295328.

78. Vollaard EJ, Clasener HAL, Van Griethuysen AJA, Janssen AJHM, Sanders-Reimers AHJ, Muller NF, et al. Influence of cefaclor, phenethicillin, co-trimoxazole and doxycycline on colonization resistance in healthy volunteers. J Antimicrob Chemother 1988;22:747-758.

79. Van der Leur JJJPM, Thunnissen PLM, Clasener HAL, Muller NF, Dofferhoff ASM. Effects of imipenem, cefotaxime and cotrimoxazole on aerobic microbial colonization of the digestive tract. Scand J Infect Dis 1993;25:473-478.

80. Vollaard EJ, Clasener HAL, Janssen AJHM. Co-trimoxazole impairs colonization resistance in healthy volunteers. J Antimicrob Chemother 1992;30:685-691.

81. Meijer-Severs GJ, Joshi JH. The effect of new broad-spectrum antibiotics on faecal flora of cancer patients. J Antimicrob Chemother 1989;24:605-613.

82. Chomarat M, Espinouse D. Lactobacillus rhamnosus septicemia in patients with prolonged aplasia receiving ceftazidime-vancomycin [letter]. Eur J Clin Microbiol Infect Dis 1991;10:44.

83. Cometta A, Calandra T, Bille J, Glauser MP. Escherichia coli resistant to fluoroquinolones in patients with cancer and neutropenia. Engl J Med 1994;330:1240-1241.

84. Kern WV, Andriof E, Oethinger M, Kern P, Hacker J, Marre R. Emergence of fluoroquinolone-resistant Escherichia coli at a cancer center. Antimicrob Agents Chemother 1994;38:681-687.

85. Kern WV, Markus A, Andriof E. Bacteremia due to fluoroquinolone resistant Escherichia coli in two immunocompromised patients. Eur J Clin Microbiol Infect Dis 1994;13:161-165.

86. Zinner SH, Calandra T, Meunier F, Gaya H, Viscoli C, Klastersky J, et al. Reduction of fever and streptococcal bacteremia in granulocytopenic patients with cancer - a trial of oral penicillin $\mathrm{V}$ or placebo combined with pefloxacin. JAMA 1994;272:1183-1189. 
87. Peters WG, Willemze R, Colly LP, Guiot HFL. Side effects of intermediate- and high-dose cytosine arabinoside in the treatment of refractory or relapsed acute leukaemia and onHodgkins lymphoma. Neth J Med 1987;30:64-74.

88. Guiot HFL, Biemond J, Klasen E, Gratama JW, Kramps JA, Zwaan FE. Protein loss during acute graft-versus-host disease: Diagnostics and clinical significane. Eur J Haematol 1987;38:187-196.

89. Callum JL, Brandwein JM, Sutcliffe SB, Scott JG, Keating A. Influence of total body irradiation on infections after autologous bone marrow transplantation. Bone Marrow Transplant 1991;8:245-251.

90. Johnson S, Driks MR, Tweten RK, Ballard J, Stevens DL, Anderson DJ, et al. Clinical courses of seven survivors of Clostridium septicum infection and their immunologic responses to a-toxin. Clin Infect Dis 1994;19:761-764.

91. Fegan C, Poynton JA, Whittaker JA. The gut mucosal barrier in bone marrow transplantation. Bone Marrow Transplant 1990;5:373-377.

92. Moody MR, Morris MJ, Young VM, Moye LA III, Schimpff SC, Wiernik PH. Effect of two cancer chemotherapeutic agents on the antibacterial activity of three antimicrobial agents. Antimicrob Agents Chemother 1978;14:737-742.

93. Jacobs JY, Michel J, Sacks T. Bactericidal effect of combinations of antimicrobial drugs and antineoplastic antibiotics against Staphylococcus aureus. Antimicrob Agents Chemother 1979;15:580-586.

94. Michel J, Jacobs JY, Sacks T. Bactericidal effect of combinations of antimicrobial drugs and antineoplastic antibiotics against gram-negative bacilli. Antimicrob Agents Chemother 1979;16:761-766.

95. Bodet CA III, Jorgensen JH, Drutz DJ. Antibacterial activities of antineoplastic agents. Antimicrob Agents Chemother 1985;28:437-439.

96. Neuman M. The antimicrobial activity of non-antibiotics - interactions with antibiotics. APMIS 1992;100(Suppl, 30):15-23.

97. Bergström P, Grankvist K, Henriksson R. Interaction between antibiotics and antineoplastic drugs on antibacterial activity in vitro: Estramustine phosphate sensitizes pneumococci to amikacin. Inte J Oncol 1994;4:43-439.

98. Van Cutsem JM, Thienpont D. Miconazole, a broad-spectrum antimycotic agent with antibacterial activity. Chemotherapy 1972;17:392-404.

99. Ware AJ, Coller BS. Platelet morphology, biochemistry, and function. In: Beutler E, Lichtman MA, Coller BS, Kipps TJ eds. Williams Hematology, (5th ed.) New York: McGraw-Hill, 1995, pp. 1161-1201.

100. Viscoli C, Bruzzi P, Castagnola E, Boni L, Calandra T, Gaya H, et al. Factors associated with bacteraemia in febrile, granulocytopenic cancer patients. Eur J Cancer 1994;30A:430-437.

101. Cronkite EP, Fliedner TM. Granulopoiesis. N Engl J Med 1964:270:1347-1352.

102. Weller PF. The immunobiology of eosinophils. N Engl J Med 1991;324:1110-1114.

103. Bodey GP, Buckley M, Sathe YS, Freireich EJ. Quantitative relationships between circulating leukocytes and infection in patients with acute leukemia. Ann Intern Med 1966:64:328340.

104. Sickles EA, Greene WH, Wiernik PH. Clinical presentation of infection in granulocytopenic patients. Arch Intern Med 1975;135:715-719.

105. EORTC International Antimicrobial Therapy Cooperative Group. Three antibiotic regimens in the treatment of infection in patients with cancer. J Infect Dis 1978;137:14-29.

106. Pizzo PA, Robichaud KJ, Wesley R, Commers JR. Fever in the pediatric and young adult patient with cancer. A prospective study of 1001 episodes. Medicine 1989;61:153-165.

107. DeGregorio MW, Lee WMF, Linker CA, Jacobs RA, Ries CA. Fungal infections in patients with acute leukemia. Am J Med 1982;73:543-548.

108. Anaissie E, Bodey GP, Kantarjian H, et al. New spectrum of fungal infections in patients with cancer. Rev Infect Dis 1989;11:369-378.

109. Bodey GP, Bueltman B, Duguid W, et al. Fungal infections in cancer patients: An international autopsy survey. Eur J Clin Microbiol Infect Dis 1992;11:99-109. 
110. Gerson SL, Talbot GH, Hurwitz S, et al. Prolonged granulocytopenia: The major risk factor for invasive pulmonary aspergillosis in patients with acute leukemia. Ann Intern Med 1984:100:345-351.

111. Young RC, Corder MP, Haynes HA, et al. Delayed hypersensitivity in Hodgkin's disease. Am J Med 1972;56:63-72.

112. Weeks JC, Tierney MR, Weinstein MC. Cost effectiveness of prophylactic intravenous immune globulin in chronic lymphatic leukemia. N Engl J Med 1991;325:81-86. 